\title{
PENGARUH ALGINAT RUMPUT LAUT SEBAGAI ZAT PENGIKAT PADA PENINGKATAN MUTU BATA MERAH PEJAL
}

\section{THE EFFECT OF SEAWEED ALGINATE AS BINDER FOR SOLID RED BRICK QUALITY IMPROVEMENT}

\author{
Subari $^{1}$ dan Kuntari Adi Suhardjo ${ }^{2}$ \\ ${ }^{1}$ Balai Besar Keramik, Jl. Jend. A. Yani 392, Bandung 40272 \\ ${ }^{2}$ Balai Besar Bahan dan Barang Teknik, Jl. Sangkuriang No. 14, Bandung 40135 \\ Email: soebary15@yahoo.com
}

Diterima: 15 September 2015

Direvisi: 24 November 2015

Disetujui: 14 Desember 2015

\begin{abstract}
ABSTRAK
Bata merah pejal adalah salah satu bahan bangunan yang hingga saat ini masih digunakan. Untuk meningkatkan kualitas bata merah pejal dapat dilakukan dengan menambahkan alginat dari rumput laut sebagai zat pengikat. Penambahan alginat ini dimaksudkan untuk meningkatkan sifat elastisitas tanah liat yang dicampur pasir. Salah satu hasil olahan dari rumput laut adalah alginat. Pada penelitian ini akan dilakukan studi tentang pengaruh komposisi bahan: tanah liat, pasir dan alginat rumput laut terhadap kualitas bata merah pejal. Dari hasil penelitian ini dapat diketahui bahwa komposisi bahan serta suhu pembakaran berpengaruh terhadap susut kering, susut bakar, susut jumlah, kuat tekan, dan daya serap air. Pada percobaan perbandingan komposisi bahan terbaik yaitu 90 (tanah liat) : 10 (pasir) : 10 (alginat) sebagai bahan aditif yang berfungsi untuk pengikat dengan temperatur pembakaran $800^{\circ} \mathrm{C}$ dimana nilai susut kering, susut bakar, susut jumlah, daya serap air, dan kuat tekan secara berurutan adalah 6,4\%; 0,95\%; 7,3\%; 37,3\%; dan 201,6 kg/ $\mathrm{cm}^{2}$. Dilihat dari nilai kuat tekannya komposisi tersebut telah memenuhi syarat mutu bata merah pejal kelas 150 .
\end{abstract}

Kata kunci: bata merah pejal, alginat rumput laut, tanah liat, pasir

\begin{abstract}
Solid red brick is one of the building materials that still used until now. The quality of solid red brick can be improved by adding alginate seaweed as a binder. The addition of alginate is intended to improve the elasticity of the clay mixed with sand. Seaweed is algae chlorophyll group, which can be found in almost all parts of Indonesia. One produced from seaweed is alginate. This research will be studied on the effect of the material composition of clay, sand and alginate on the quality of solid red brick. It can be seen from these results that the composition of the material and the combustion temperature give effect on dry shrinkage, shrinkage fuel, shrinkage amount, compressive strength, and water absorption. In the main trial produced the best material composition ratio of 90 (clay) : 10 (sand) : 10 (alginate) as additive for binder with a firing temperature of $800^{\circ} \mathrm{C}$ while the value of dry shrinkage, firing shrinkage, total of shrinkage, water absorption and compressive strength are 6.4\%; 0.95\%; 7.3\%; $37.3 \%$ and $201.6 \mathrm{~kg} / \mathrm{cm}^{2}$, respectively. Based on the compressive strength value, such composition has fulfilled the requirement for solid red brick class 150.
\end{abstract}

Keywords: solid red brick, seaweed alginate, clay, sand

\section{PENDAHULUAN}

Salah satu mahluk hidup yang tumbuh dan berkembang di laut adalah rumput laut (algae). Alginat adalah salah satu jenis rumput laut yang tumbuh dan berkembang di laut serta mempunyai sifat lengket atau plastis seperti tanah liat atau lempung [1]. Dari ratusan jenis rumput laut yang hidup, terdapat tiga jenis yang mempunyai nilai ekonomi yang tinggi dan berpotensi besar untuk dibudidayakan, yaitu agar-agar, karaginan, dan alginat. Hal ini dikarenakan penggunaannya yang luas dalam industri makanan, kosmetik, tekstil, farmasi dll.

Alginat merupakan bagian dari dinding sel yang terdapat pada rumput laut coklat (brown seaweeds). Jenis rumput laut coklat penghasil alginat ini biasanya hidup pada daerah sub tropis 
terutama pada jenis Macrocytis, Laminaria, Aschophyllum, Nerocytis, Ecklonia, Fucus dan Sargassum [1]. Namun ada pula rumput laut yang hidup pada daerah tropis seperti di Indonesia terutama jenis Sargassum, Turbinaria, Padina, Dyctyota dan yang paling banyak ditemukan adalah jenis Sargassum dan Turbinaria.

Alginat pada industri keramik dipakai sebagai bahan pengikat atau binder [2,3]. Salah satu produk keramik yang banyak dibutuhkan untuk bahan bangunan adalah bata merah pejal. Dalam pembuatan bata merah digunakan alginat sebagai bahan untuk meningkatkan sifat keplastisan bata agar mudah dicetak atau dibentuk terutama untuk bata merah yang konstruksi dinding bangunannya tidak diplester [4], dengan hipotesis bahwa alginat dapat meningkatkan kualitas bata merah pejal karena sifat keplastisannya.

Pada penelitian ini dilakukan penentuan keplastisan tanah liat, persentase kadar lempung dalam tanah liat, kadar air pembentuknya dan penentuan pengaruh alginat terhadap masingmasing bahan.

Tujuan penelitian ini adalah untuk mempelajari pengaruh perbandingan komposisi alginat dengan tanah liat terhadap kualitas bata merah pejal. Selain itu, juga untuk mempelajari pengaruh suhu pembakaran terhadap kualitas bata merah pejal, serta untuk mengetahui proses pembuatan bata merah pejal dan kualitas bata merah pejal di industri keramik dapat ditingkatkan.

\section{BAHAN DAN METODE}

\section{Bahan dan Alat}

Bahan baku yang digunakan untuk penelitian ini adalah tanah liat dari daerah Nanjung-Cipatik Cimahi, pasir, dan alginat. Alat-alat yang digunakan adalah jaw crusher, ayakan standar ukuran 60 mesh, cetakan spesimen uji dan cetakan bata merah pejal, tungku listrik, alat uji kuat tekan (Universal Testing Machine), dan alat caliper (jangka sorong).

\section{Prosedur Percobaan}

Percobaan yang dilakukan dalam penelitian ini dibagi menjadi dua tahap. Sebelum dilakukan percobaan, tanah liat ini diamati dahulu kandungan kadar tanah liat (clay substance) dan kadar pasirnya, selanjutnya ditentukan komposisi bahan baku bata merah pejal yaitu tanah liat, pasir, dan air, serta kadar air pembentuk [5,6].

\section{Prosedur Percobaan Tahap Pertama}

Tujuan percobaan ini adalah untuk mengetahui pengaruh komposisi bahan yaitu tanah liat, pasir dan alginat terhadap kualitas bata merah pejal pada suhu $800^{\circ} \mathrm{C}$. Komposisi pertama adalah sebagai berikut:

Tabel 1. Komposisi Bahan dan Proses Percobaan Tahap Pertama pada Suhu $800^{\circ} \mathrm{C}$

\begin{tabular}{|c|c|c|c|}
\hline \multirow{2}{*}{ No. } & \multicolumn{3}{|c|}{ Perbandingan Berat (\%berat) } \\
\hline & Tanah Liat & Pasir & Alginat \\
\hline 1 & 90 & 10 & 10 \\
\hline 2 & 60 & 40 & 10 \\
\hline $\begin{array}{l}\text { Prosedur } \\
\text { percobaan }\end{array}$ & $\begin{array}{l}\text { Ditambah ai } \\
\text { lengket di ta } \\
\text { uji, diuji k} \\
\text { bahan, dan } \\
\text { bahan terh } \\
\text { merah pejal. }\end{array}$ & $\begin{array}{l}\text { ingga } \\
\text { \{an, ce } \\
\text { lar air, } \\
\text { engaru } \\
\text { lap } \quad k\end{array}$ & $\begin{array}{l}\text { stis, tidak } \\
\text { spesimen } \\
\text { eplastisan } \\
\text { komposisi } \\
\text { tas bata }\end{array}$ \\
\hline
\end{tabular}

Selanjutnya komposisi kedua adalah sebagai berikut:

Tabel 2. Komposisi Bahan dan Proses Percobaan sebagai Pembanding Tahap Pertama pada Suhu $800^{\circ} \mathrm{C}$

\begin{tabular}{|c|c|c|c|}
\hline \multirow{2}{*}{ No. } & \multicolumn{3}{|c|}{ Perbandingan Berat (\%berat) } \\
\hline & Tanah Liat & Pasir & Alginat \\
\hline 1 & 100 & 0 & 0 \\
\hline 2 & 90 & 10 & 0 \\
\hline 3 & 90 & 0 & 10 \\
\hline 4 & 60 & 0 & 40 \\
\hline $\begin{array}{l}\text { Prosedur } \\
\text { percobaan }\end{array}$ & \multicolumn{3}{|c|}{$\begin{array}{l}\text { Ditambah air hingga plastis, tidak } \\
\text { lengket di tangan, cetak spesimen } \\
\text { uji, dikeringkan diuji susut kering. } \\
\text { Selanjutnya dibakar pada suhu } \\
800^{\circ} \mathrm{C} \text { diuji susut bakar, daya } \\
\text { serap air, porositas dan kuat } \\
\text { tekan. }\end{array}$} \\
\hline
\end{tabular}

\section{Prosedur Percobaan Tahap Kedua}

Pada percobaan ini, berdasarkan percobaan pertama dimaksudkan untuk mencari kondisi optimum percobaan pada variasi suhu pembakaran $800^{\circ} \mathrm{C}, 850^{\circ} \mathrm{C}$ dan $950^{\circ} \mathrm{C}$ adalah sebagai berikut: 
Tabel 3. Komposisi Bahan dan Proses Percobaan sebagai Pembanding Tahap Kedua pada Suhu $800^{\circ} \mathrm{C}, 850^{\circ} \mathrm{C}$ dan $900^{\circ} \mathrm{C}$

\begin{tabular}{|c|c|}
\hline \multirow{2}{*}{ No. } & Perbandingan Berat (\% berat) \\
\hline & Pasir Alginat \\
\hline 1 & 90 \\
\hline 2 & 40 \\
\hline 3 & 100 \\
\hline $\begin{array}{l}\text { Prosedur } \\
\text { percobaan }\end{array}$ & $\begin{array}{l}\text { Ditambah air hingga plastis, } \\
\text { tidak lengket di tangan, cetak } \\
\text { spesimen uji, dikeringkan diuji } \\
\text { susut kering. Selanjutnya } \\
\text { dibakar pada suhu } 800^{\circ} \mathrm{C} \text {, } \\
850^{\circ} \mathrm{C} \text {, dan suhu } 900^{\circ} \mathrm{C} \text { diuji } \\
\text { susut bakar, daya serap air, } \\
\text { porositas, dan kuat tekan. }\end{array}$ \\
\hline
\end{tabular}

\section{Pengujian}

Pengujian sifat mekanik bata merah pejal diuji sesuai dengan SNI 15-2094-2000. Syarat Mutu untuk kuat tekan kelas 50 bila kuat tekan minimum $50 \mathrm{~kg} / \mathrm{cm}^{2}$, kelas 100 bila kuat tekan minimum $100 \mathrm{~kg} / \mathrm{cm}^{2}$, dan kelas 150 bila kuat tekan $150 \mathrm{~kg} / \mathrm{cm}^{2}$. Nilai penyerapan air maksimum 20\%. Untuk pengujian kuat tekan dilakukan menurut prosedur uji pada butir 7.3 dan untuk pengujian daya serap air (penyerapan air menurut prosedur uji pada butir 7.4 SNI.152094-2000 [7].

Cara pengujiannya adalah spesimen yang masih basah dikeringkan pada suhu kamar yang dilanjutkan dengan pengeringan menggunakan oven pengering pada temperatur $105^{\circ} \mathrm{C}$.

\section{HASIL DAN PEMBAHASAN}

\section{Pengujian Nilai Kadar Air Pembentuk}

Kandungan dalam tanah liat berupa 74,8\% fraksi lempung (clay) dan 25,2\% fraksi pasir, yang artinya tanah liat tersebut bersifat kurang plastis [8]. Namun demikian tanah liat ini masih bisa digunakan sebagai bahan baku untuk pembuatan bata merah pejal bilamana diberi bahan aditif seperti CMC, alginat, water glass dan dekstrin, yang mana bahan aditif tersebut berfungsi sebagai pengikat (binder). Tanah liat yang diteliti ini setelah dibakar pada suhu tinggi $\left(800^{\circ} \mathrm{C}\right)$ memberikan warna merah karena mengandung kadar besi oksida $\left(\mathrm{Fe}_{2} \mathrm{O}_{3}\right)$ sekitar 7$10 \%$ serta mengandung mineral goethite, hematite, illite, dan mineral lempung yang kaya kandungan alkali $[9,10]$. Penentuan sifat keplastisan tanah liat tersebut dilakukan secara tradisional, terlihat pada bagian permukaan spesimen mengalami sedikit retak rambut yang artinya tanah liat tersebut bersifat kurang plastis. Tanah liat setelah ditambah dengan alginat yang fungsinya sebagai pengikat (binder) dapat bersifat plastis dibandingkan dengan tanah liat sebelum ditambah bahan alginat. Kemudian, ditentukan pengaruh alginat terhadap masingmasing bahan (tanah liat dan pasir) dengan perbandingan tanah liat:pasir:alginat sebagai berikut: 90:10:0; 90:0:10; dan 60:0:40, yang dibakar pada temperatur $800^{\circ} \mathrm{C}$, dimana komposisi bahan tersebut diatas akan dibandingkan dengan bata merah pejal yang komposisi tanah liat:pasir:alginat adalah 100:0:0. Masingmasing komposisi campuran bahan yang dicoba dibuat spesimen, sehingga nilai kadar air pembentukan dapat dihitung, yang hasil perhitungannya dapat dilihat pada Tabel 4 .

Tabel 4. Nilai Kadar Air Pembentuk pada Berbagai Komposisi Campuran Bahan

\begin{tabular}{cc}
\hline $\begin{array}{c}\text { Tanah Liat:Pasir:Alginat } \\
\text { (\% berat) }\end{array}$ & $\begin{array}{c}\text { Kadar air } \\
\text { pembentuk } \\
(\%)\end{array}$ \\
\hline $100: 0: 0$ & 28,90 \\
\hline $90: 10: 0$ & 28,54 \\
\hline $90: 0: 10$ & 28,35 \\
\hline $60: 0: 40$ & 27,96 \\
\hline $60: 40: 0$ & 30,17 \\
\hline
\end{tabular}

Berdasarkan Tabel 4 tersebut, tanah liat yang berasal dari Nanjung-Cipatik (sebelum dan sesudah ditambah alginat) memiliki nilai kadar air pembentuk berkisar antara 27,96-30,17\%. Pada percobaan berikutnya, keempat komposisi bahan yang diteliti digunakan untuk pembuatan bata merah pejal.

\section{Pengujian Nilai Susut Kering}

Hasil analisis nilai susut kering pada masing-masing komposisi dapat dilihat pada Tabel 5. Pada Tabel 5 terlihat bahwa nilai susut kering pada perbandingan komposisi 90:0:10 lebih kecil dibandingkan dengan perbandingan komposisi 60:0:40, karena bahan alginat ini merupakan bahan pengikat organik yang memiliki sifat susut yang cukup besar. Disamping itu, kemungkinan besar disebabkan oleh air yang terikat pada alginat berada dalam jumlah banyak karena alginat memiliki sifat mudah menyerap air sehingga ketika akan dikeringkan airnya cepat menguap. Namun, air 
yang mengikat mineral dalam spesimen semakin banyak sehingga susut kering akan semakin besar. Sedangkan, komposisi 90:10:0 nampak lebih kecil bila dibandingkan dengan nilai bata merah pejal yang merupakan bata standar yang dibuat di daerah Nanjung-Cipatik.

Tabel 5. Nilai Susut Kering Spesimen Bata Merah Pejal

\begin{tabular}{cc}
\hline Tanah Liat:Pasir:Alginat & $\begin{array}{c}\text { Susut kering } \\
(\%)\end{array}$ \\
\hline $100: 0: 0$ & 5,83 \\
\hline $90: 10: 0$ & 5,36 \\
\hline $90: 0: 10$ & 6,56 \\
\hline $60: 0: 40$ & 10,90 \\
\hline
\end{tabular}

Bahan pasir yang dicampur berfungsi sebagai pengendali susut, sehingga dapat mengurangi sifat susut kering. Selain itu, air yang terikat pada mineral lempung dalam bata merah standar tidak begitu banyak sehingga tanah liat akan menyusut lebih kecil. Kondisi spesimen pada kedua perbandingan yang terlalu peka terhadap temperatur di lingkungan pembakaran dapat menyebabkan susut menjadi sangat besar. Sedangkan, pada perbandingan 90:10:0 memiliki nilai susut kering lebih kecil bila dibandingkan dengan nilai susut kering bata merah standar. Hal ini menunjukkan bahwa pasir yang dominan mengandung mineral kuarsa/silika berperan penting sebagai pengendali susut kering, sehingga dalam proses pencetakan bata akan menjadi lebih baik [11].

\section{Pengujian Nilai Susut Bakar dan Nilai Susut Jumlah}

Hasil analisis menunjukkan bahwa nilai susut bakar pada bata merah pejal standar lebih besar dibandingkan dengan nilai susut bakar pada 90:10:0. Hal ini disebabkan pada perbandingan 90:10:0, ikatan antara mineral di dalam tanah liat dengan mineral di dalam pasir lebih kuat dan didukung dengan peran pasir yang dapat menurunkan nilai susut bakar. Sedangkan, pada perbandingan komposisi 90:0:10 dan 60:0:40 memiliki nilai susut bakar yang lebih besar dibandingkan dengan nilai susut bakar pada bata standar. Hal ini disebabkan oleh meleburnya kandungan alkali tanah diikuti dengan leburnya alginat ketika dibakar pada suhu diatas $750^{\circ} \mathrm{C}$, sehingga ikatan antara partikel di dalam benda coba akan semakin besar dan pori-porinya akan semakin mengecil. Pada perbandingan komposisi 90:0:10 memiliki nilai susut bakar yang lebih besar dibandingkan dengan perbandingan 60:0:40 dikarenakan adanya ikatan antara alginat dengan tanah liat yang tidak sempurna. Ikatan yang tidak sempurna ini dapat disebabkan oleh waktu penahanan pada saat pembakaran yang kurang lama sehingga terdapat partikel-partikel pada sampel benda uji yang tidak terbakar secara merata. Nilai susut bakar ini akan memiliki kecenderungan yang sama dengan susut jumlah. Hasil analisis susut bakar (Gambar 1) dan susut jumlah (Gambar 2) sebagai berikut:

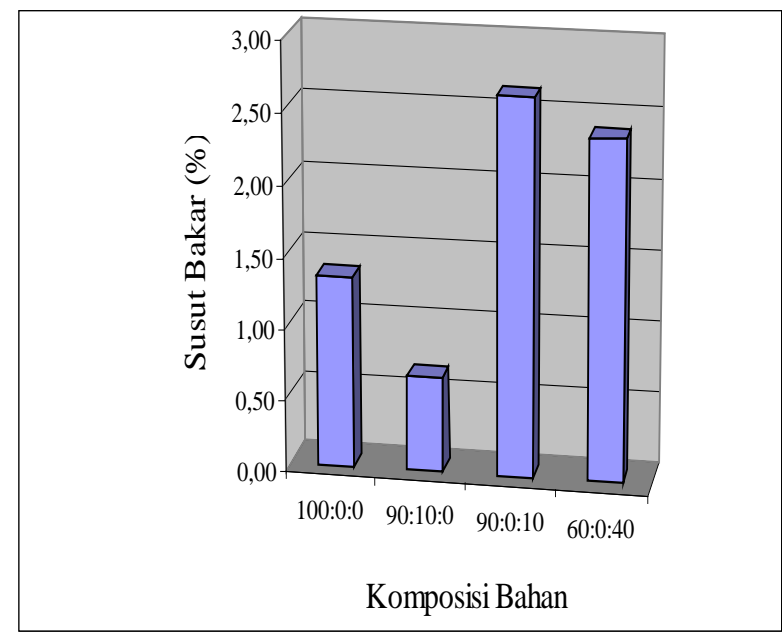

Gambar 1. Pengaruh Komposisi Bahan terhadap Susut Bakar pada Suhu Pembakaran $800^{\circ} \mathrm{C}$

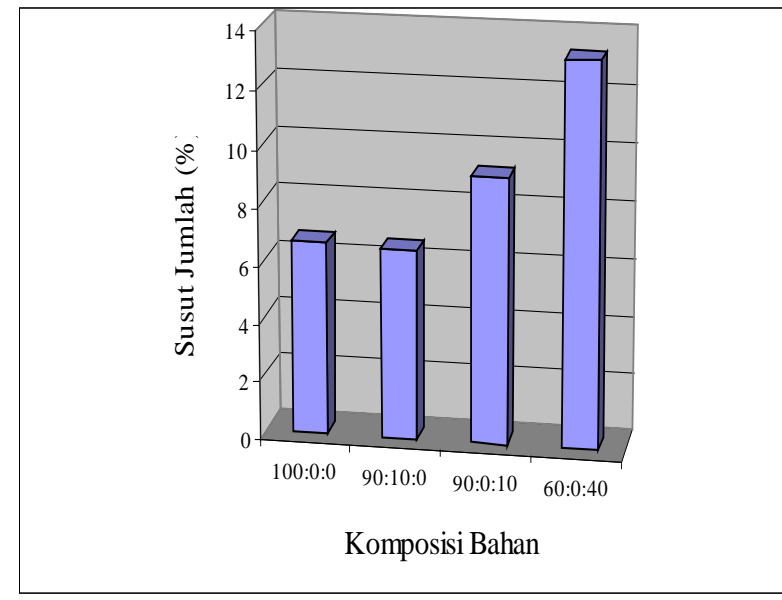

Gambar 2. Pengaruh Komposisi Bahan terhadap Susut Jumlah pada Suhu Pembakaran $800^{\circ} \mathrm{C}$ 
Pada analisis porositas, bata merah pejal untuk komposisi 100:0:0 yang merupakan bata standar perajin, memiliki porositas yang lebih kecil dibandingkan dengan yang perbandingan komposisi 90:10:0.

Hal ini disebabkan nilai daya serap air (penyerapan air) untuk bata standar lebih kecil sehingga nilai porositas pada bata lebih kecil pula. Hal ini menyebabkan pula nilai kuat tekan menjadi lebih besar. Sedangkan, pada perbandingan komposisi 90:0:10 dan 60:0:40 memiliki nilai porositas yang lebih kecil dibandingkan dengan nilai porositas pada bata merah standar. Hal ini disebabkan meleburnya alginat ketika dibakar sehingga alginat tersebut akan mengisi pori-pori pada benda coba dan menyebabkan porositas dan daya serap air semakin kecil. Selain itu, nilai kuat tekan yang dimiliki lebih besar dibandingkan dengan bata merah standar. Sedangkan pada perbandingan komposisi 90:0:10 memiliki nilai porositas dan daya serap air yang lebih kecil dibandingkan dengan perbandingan 60:0:40. Hal ini disebabkan karena pada perbandingan 90:0:10 lebih sedikit menyerap air karena sebagian lubang pori-pori sudah menutup. Selain itu, pada perbandingan komposisi 60:0:40 ketika dibakar partikelpartikel di dalam benda coba tidak mengikat secara sempurna karena waktu penahanan yang kurang lama atau dapat disebabkan pembakaran yang tidak merata sehingga ikatan partikelpartikelnya kurang kuat serta lubang pori-porinya belum menutup.

\section{Pengujian Daya Serap Air dan Kuat Tekan}

Hasil analisis daya serap air dan kuat tekan dapat dilihat pada Gambar 3 dan Gambar 4 sebagai berikut:

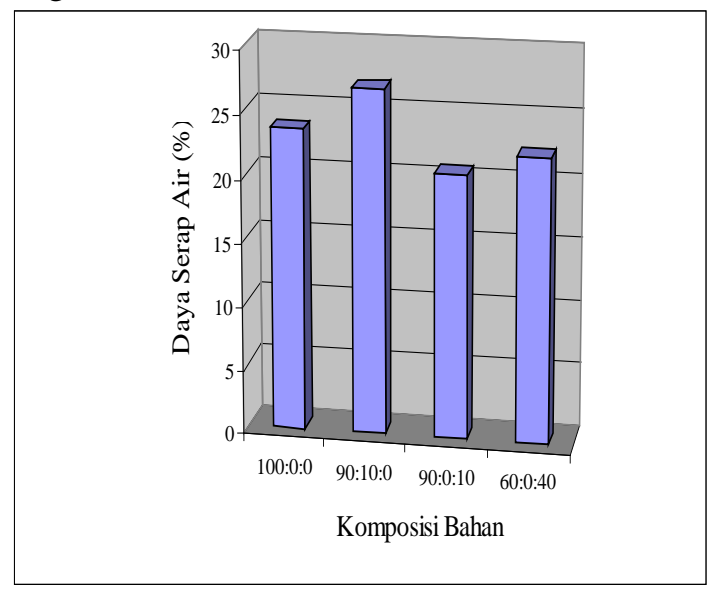

Gambar 3. Pengaruh Komposisi Bahan terhadap Daya Serap Air pada Suhu Pembakaran $800^{\circ} \mathrm{C}$.

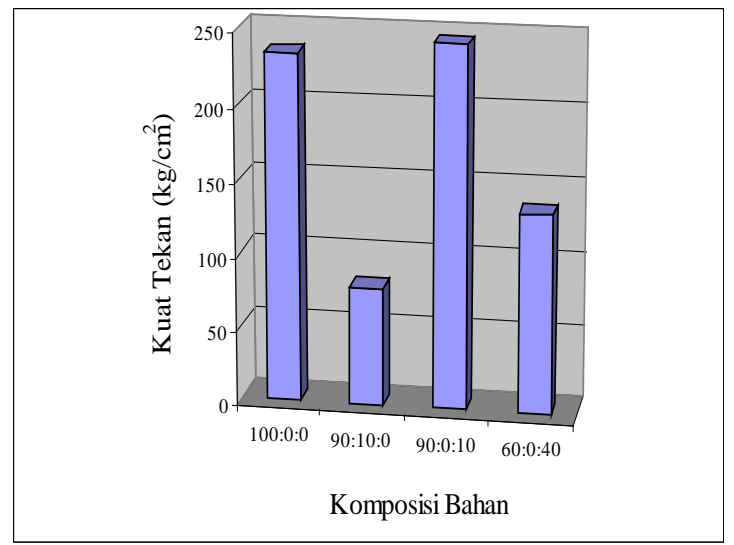

Gambar 4. Pengaruh Komposisi Bahan terhadap Kuat Tekan pada Suhu Pembakaran $800^{\circ} \mathrm{C}$.

Pada percobaan tahap pertama, analisis susut kering untuk perbandingan komposisi 60:0:40 memiliki nilai susut kering yang cukup tinggi dibandingkan dengan perbandingan komposisi yang lain. Hal ini disebabkan perbandingan komposisi 60:0:40 tersebut memiliki sifat yang sangat plastis dengan pemakaian alginat sebesar $40 \%$ yang mengakibatkan kadar air pembentuk cukup besar sehingga dengan bertambahnya keplastisan terhadap komposisi tersebut diatas maka susut kering akan semakin tinggi.

\section{Hasil Analisis antara Percobaan Tahap Pertama dan Percobaan Tahap Kedua dengan Adanya Peningkatan Suhu $800^{\circ} \mathrm{C}, 8^{\circ} 0^{\circ} \mathrm{C}$ dan $900^{\circ} \mathrm{C}$}

\section{Pengujian Susut Bakar dan Susut Jumlah}

Pada analisis susut bakar seiring dengan meningkatnya temperatur pembakaran, nilai susut bakar cenderung semakin meningkat. Hal ini dikarenakan semakin tinggi temperatur pembakaran maka ikatan antara partikel-partikel tanah liat dan alginat semakin merekat kuat sehingga susut pada pembakaran suhu tinggi semakin besar, begitu pula dengan kecenderungan meningkat yang dimiliki oleh susut jumlah. Adapun hasil uji susut bakar pada Gambar 5 dan susut jumlah pada Gambar 6 sebagai berikut:

Untuk analisis porositas, pada perbandingan komposisi 100:0:0 memiliki nilai porositas dan daya serap air (penyerapan air) yang cenderung menurun, sehingga nilai kuat tekan pun akan meningkat. Sedangkan, pada perbandingan 90:10:0 memiliki kuat tekan yang lebih kecil karena adanya penambahan pasir 
sehingga pori-pori dan daya serap air semakin meningkat. Pada perbandingan komposisi 90:10:10 memiliki porositas dan daya serap air yang cenderung lebih kecil seiring dengan meningkatnya temperatur pembakaran bila dibandingkan dengan perbandingan komposisi 60:0:40.

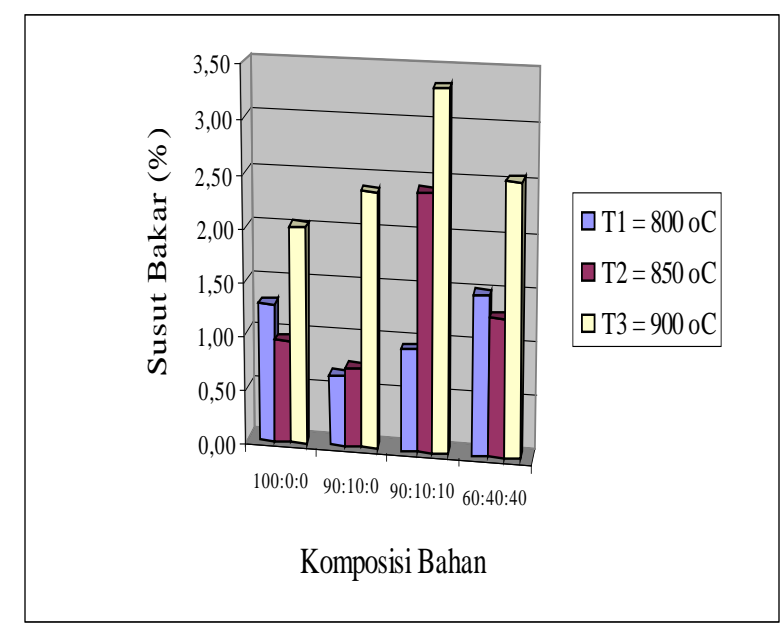

Gambar 5. Pengaruh Suhu Pembakaran dan Komposisi Bahan terhadap Susut Bakar

Hal ini disebabkan pada perbandingan 90:10:10 lebih cepat mencapai temperatur sintering sehingga ikatan antara partikel di dalam benda coba lebih kuat dibandingkan dengan perbandingan 60:40:10 sehingga pada perbandingan komposisi 90:10:10 memiliki nilai kuat tekan yang lebih besar dibandingkan dengan yang perbandingan komposisi 60:40:40, serta komposisi tersebut telah memenuhi kualitas standar [10].

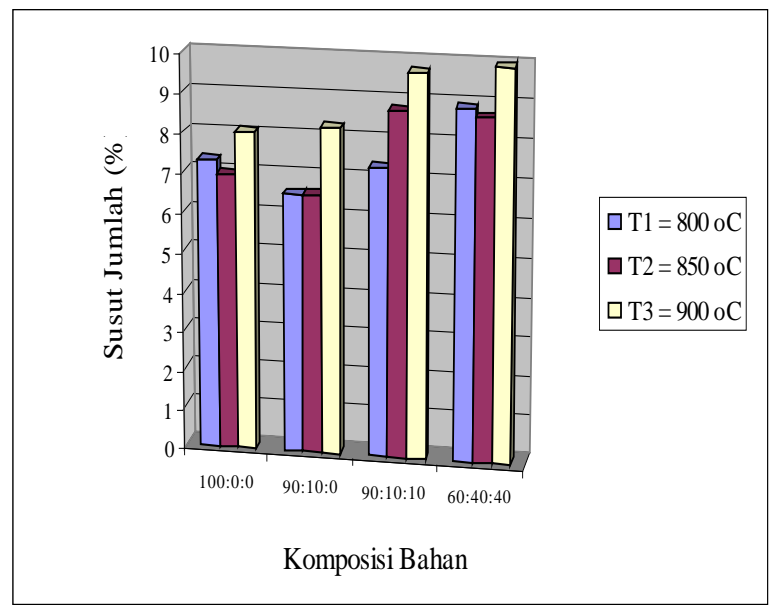

Gambar 6. Pengaruh Suhu Pembakaran dan Komposisi Bahan terhadap Susut Jumlah

\section{Pengujian Daya Serap Air, Porositas dan Kuat Tekan}

Hasil analisis nilai daya serap air, porositas, dan kuat tekan dapat dilihat masingmasing pada Gambar 7, Gambar 8, dan Gambar 9.

Untuk semua komposisi campuran bahan baku yang dibuat spesimen serta dibakar pada temperatur $800-900^{\circ} \mathrm{C}$ [11] nilai kuat tekannya sudah memenuhi syarat mutu bata merah pejal kelas $50 \mathrm{~s} / \mathrm{d}$ 150, bahkan kuat tekan yang untuk komposisi 90:10:10 sebagai aditif memiliki nilai kuat tekan diatas $150 \mathrm{~kg} / \mathrm{cm}^{2}$ serta dapat meningkatkan kualitas bata merah dibandingkan dengan komposisi yang tanpa bahan alginat.

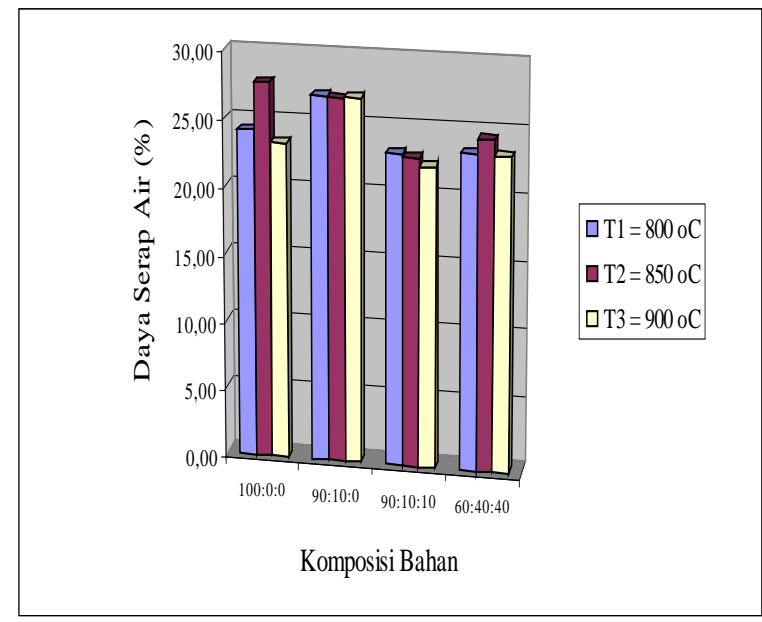

Gambar 7. Pengaruh Suhu Pembakaran dan Komposisi Bahan terhadap Daya Serap Air

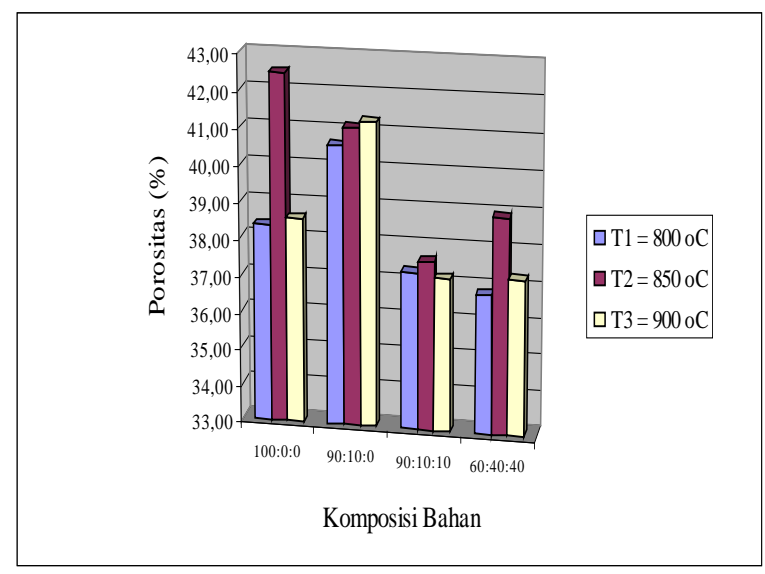

Gambar 8. Pengaruh Suhu Pembakaran dan Komposisi Bahan terhadap Porositas 


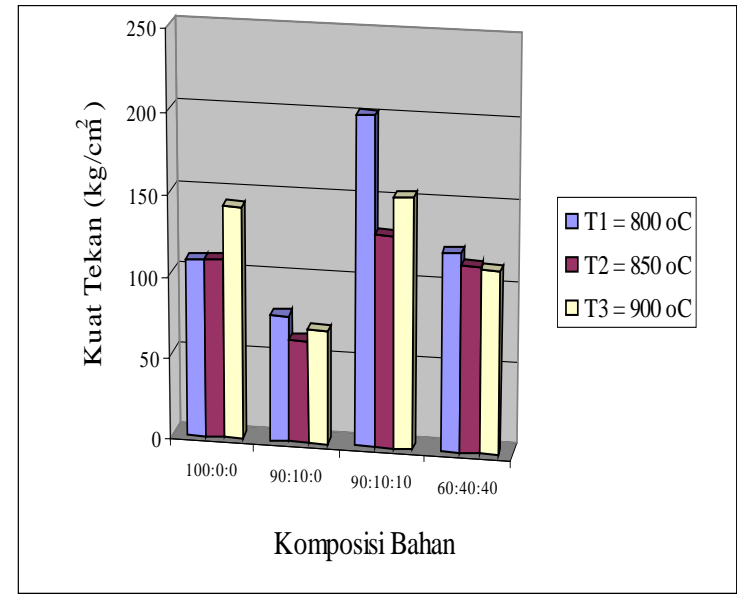

Gambar 9. Pengaruh Suhu Pembakaran dan Komposisi Bahan terhadap Kuat Tekan

\section{KESIMPULAN}

Komposisi campuran bahan baku dan temperatur pembakaran berpengaruh terhadap susut kering, susut bakar, susut jumlah, daya serap air (penyerapan air), dan kuat tekan.

Alginat sebagai pengikat di dalam campuran tanah liat dan pasir dapat menurunkan kualitas apabila terdapat banyak partikel-partikel kasar yang tidak dapat diikat, demikian sebaliknya bilamana partikel-partikel kasarnya sedikit dapat meningkatkan kualitas bata merah.

Temperatur pembakaran $800^{\circ} \mathrm{C}$ merupakan kondisi pembakaran terbaik untuk perbandingan komposisi bahan 90:10:10 sebagai bahan aditif dengan nilai susut kering, susut bakar, susut jumlah, daya serap air, dan kuat tekan masingmasing yaitu 6,37\%; 0,95\%; 7,32\%; 17,29\%; dan $201,59 \mathrm{~kg} / \mathrm{cm}^{2}$.

\section{UCAPAN TERIMA KASIH}

Dengan dapat diselesaikannya karya tulis ilmiah ini, penulis mengucapkan terima kasih kepada Teresa Amelia, Any Rumiati dan Muhtar atas bantuan tenaga dan pikiran selama melakukan kegiatan penelitian ini.

\section{DAFTAR PUSTAKA}

[1] Amir Husni, Subaryono, dan Yudi Pranoto, 2012, "Pengembangan Metode Ekstraksi Alginat dari Rumput Laut sebagai Bahan Pengental”, Agritech Journal, 32 (1).

[2] Anonymous, "Alginate Based Building Materials”, US. Pat 20120040093.
[3] Mohammad Shahid Arshad dan PY. Pawade, 2014, "Reuse of Natural Waste Material for Making Bricks", International Journal of Scientific and Technology Research, 3 (6).

[4] Fong Lin, Deng, Huan-Lin Luo, dan ShuWen Zhang, 2007, "Effects of Nano-SiO On Tiles Manufactured with Clay and Incinerated Sewage Sludge Ash”, Journal of Materials in Civil Engineering, 19 (10).

[5] Rouf, Abdur, dan Md. Delwar Hossain, 2000, Effects of Using Arsenic-Iron Sludge in Brick Making, Department of Civil Engineering, Bangladesh University of Engineering and Technology, Dhaka.

[6] Baskar, R., K.M. Meera Sherifa Begum, dan S. Sundaram, 2006, "Characterization and Reuse of Textile Effluent Treatment Plant Waste Sludge in Clay Bricks", Journal of the University of Chemical Technology and Metallurgy, 14 (4), 473478.

[7] Anonim, 2000, "Bata Merah Pejal”, SNI 15-2094-2000, BSN, Jakarta.

[8] Gesang S dan Hartono YMV, 1978, Teknologi Bahan Bangunan Bata dan Genteng, Balai Besar Penelitian dan Pengembangan Industri Keramik, Bandung.

[9] Philppe Boch dan Jean Claud Niepce, 2007, Ceramic Materials, Process, Properties and Application, ISTE, USA.

[10] Djambazov SP, Yoleva AP, dan Malinov OK., 2009, "Red Firing Ceramic Bodies for Clinker tiles and Bricks” Tile and Brick International, 8 (1).

[11] Kute, S., dan S.V.Deodhar, 2003, "Effect of Fly Ash and Temperature on Properties of Burnt Clay Bricks”, Journal of Civil Engineering, 84 (2), 2003. 
Jurnal Teknologi Bahan dan Barang Teknik Vol. 5, No.2, Desember 2015 : 45-52 